\title{
Nutritional status of snack takers after evening meal in Korea: from the 2005 Korean National Health and Nutrition Examination Survey
}

\author{
Eun-Kyoung Lee and Young-Jin Chung \\ Department of Food and Nutrition, College of Human Ecology, Chungnam National University, Republic of Korea
}

To investigate the nutritional status of snack takers after evening meal in Korea, 3903 subjects 20 years and above without illness were selected and their anthropometry, blood biomarkers and food and nutrients intake were analysed from the data 2005 Korean Health and Nutrition Examination Survey. The subjects were divided into three groups according to energy intake from the night snack; $0 \mathrm{~kJ}(0 \mathrm{kcal})$, $4.184-2087.816 \mathrm{~kJ}(1-499 \mathrm{kcal}), 2092 \mathrm{~kJ}$ ( $\geq 500 \mathrm{kcal})$ by using the 24 -h recall data. The non-snack group was $66.0 \%$, the snack group under $2092 \mathrm{~kJ}$ ( $500 \mathrm{kcal})$ was $28.4 \%$ and the snack group above $2092 \mathrm{~kJ}(500 \mathrm{kcal})$ was $5.6 \%$ of all the subjects. Most of the men and the young-aged are included in the group taking night snack above $2092 \mathrm{~kJ}(500 \mathrm{kcal})$. When adjusted with sex and age, night snack energy was positively correlated with waist circumference, Glu-FBS, Glu-PP120 and also positively correlated with the daily intake of many nutrients and food group such as meat and egg, beverages and alcohols. When adjusted with energy intake, the snack group above $2092 \mathrm{~kJ}$ $(500 \mathrm{kcal})$ took more alcohol, fat, potassium, retinol, riboflavin and water, while it took less carbohydrate, dietary fibre, calcium, phosphorus, iron, sodium, vitamin A and $\beta$-carotene compared to the rest of the two groups. Especially alcohol intake is about six times higher compared to the other two groups. When adjusted with energy intake, the snack energy showed positive correlation with just the intake of water, fat and alcohol. The night snack group above $2092 \mathrm{~kJ}(500 \mathrm{kcal})$ showed the lowest carbohydrate energy ratio of $51.5 \pm 13.6 \%$ and the highest fat energy ratio of $21.08 \pm 8.49 \%$ among the three groups, while the no or less snack group showed carbohydrate energy ratio of $64.88 \pm 12.31,63.44 \pm 10.85$ and fat energy ratio of $17.39 \pm 8.85,18.84 \pm 8.06$ individually. This result suggests that habitual snacking above $2092 \mathrm{~kJ}$ ( $500 \mathrm{kcal}$ ) after evening meal could lead to the unbalanced diet with high-energy and lownutrient density. 